Pesq. Vet. Bras. 35(2):141-147, fevereiro 2015 DOI: $10.1590 /$ S0100-736X2015000200008

\title{
Identificação e genotipagem de Mycobacterium bovis em bovinos positivos no teste intradérmico para tuberculose em Mato Grosso do Sul ${ }^{1}$
}

\author{
Daniela de O. Cazola ${ }^{2 *}$, Klaudia dos S.G. Jorge², Martín J. Zumárraga ${ }^{3}$, Antônio F. \\ Souza-Filho ${ }^{4}$, Flábio R. Araújo ${ }^{5}$ e Ana Luiza A.R. Osório ${ }^{2}$
}

\begin{abstract}
Cazola D.O., Jorge K.S.G., Zumárraga M.J., Souza-Filho A.F., Araújo F.R. \& Osório A.L.A.R. 2015. [Identification and genotyping of Mycobacterium bovis from positive cattle in skin test for tuberculosis in the State of Mato Grosso do Sul, Brazil.] Identificação e genotipagem de Mycobacterium bovis em bovinos positivos no teste intradérmico para tuberculose em Mato Grosso do Sul. Pesquisa Veterinária Brasileira 35(2):141-147. Laboratório de Micobacteriologia e Biologia Molecular, Faculdade de Medicina Veterinária e Zootecnia, Universidade Federal de Mato Grosso do Sul, Av. Senador Filinto Müller 2443, Campo Grande, MS 79074-460, Brazil. E-mail: danicazola@gmail.com

Spoligotyping was performed in the present study to genotype Mycobacterium bovis isolates obtained from tissues of cattle that were positive in the comparative intradermal tuberculin test (CITT) in the state of Mato Grosso do Sul (Brazil). Tissue samples from 13 positive cattle from different municipalities of the state were cultured using a Stonebrink medium. The resulting colonies were subjected to Ziehl-Neelsen staining and all isolates exhibited the staining characteristics of AFB. The 13 isolates of AFB were identified by means of a multiplex PCR (mPCR) assay. The hsp65 gene was targeted for the identification of Mycobacterium spp., whereas the IS6110 insertion sequence was targeted for the identification of the Mycobacterium tuberculosis complex (MTC) and the rvd1rv2031c region was explored for the detection of Mycobacterium bovis. The spoligotyping assay was performed to genotype mycobacterial isolates. Of the 13 cattle, seven had at least one lesion suggestive of tuberculosis in the retropharyngeal, parotid and lung lymph nodes or lung. The remaining six exhibited no lesions suggestive of the disease. In the MPCR, 11 of the 13 isolates (84.6\%) were positive for Mycobacterium spp., 8/13 (61.5\%) were positive for the MTC and 7/13 (53.8\%) were positive for M. bovis. Based on the spoligotyping, eight isolates were grouped into three different groups of genotypes and one isolate exhibited an orphan type. Four isolates exhibited spoligotype pattern SB0121, while two isolates were associated with the pattern SB1145, another two were associated with pattern SB0881 and one was associated with pattern SB0140. Spoligotyping confirmed the genetic diversity present among isolates found in the state of Mato Grosso do Sul. In addition, SB0121 was confirmed as the predominant profile.
\end{abstract}

INDEX TERMS: Mycobacterium bovis, molecular identification, molecular epidemiology, spoligotyping, bovine tuberculosis.

RESUMO.- Neste estudo, realizou-se genotipagem de isolados de Mycobacterium bovis, provenientes de amostras de tecidos de bovinos positivos no teste cervical compa-

\footnotetext{
${ }^{1}$ Recebido em 26 de junho de 2014.

Aceito para publicação em 5 de março de 2015

${ }^{2}$ Programa de Pós-graduação em Ciência Animal, Faculdade de Medicina Veterinária e Zootecnia (FAMEZ), Universidade Federal de Mato Grosso do Sul (UFMS), Laboratório de Micobacteriologia e Biologia Molecular, Av. Senador Filinto Müller 2443, Campo Grande, MS 79074-460, Brasil. *Autor para correspondência: danicazola@gmail.com
}

rativo (TCC) para tuberculose em Mato Grosso do Sul, por meio da técnica de spoligotyping. Tecidos de 13 bovinos positivos, oriundos de diferentes municípios do estado,

\footnotetext{
${ }^{3}$ Instituto de Biotecnología, CICVyA-INTA Castelar, CC 25,1712 Castelar, Buenos Aires, Argentina.

${ }^{4}$ Residente em medicina veterinária no Laboratório de Micobacteriologia e Biologia Molecular, FAMEZ-UFMS,. Av. Senador Filinto Müller 2443, Campo Grande, MS.

${ }^{5}$ Embrapa Gado de Corte, Avenida Rádio Maia 830, Vila Popular, Campo Grande, MS 79106-550, Brasil.
} 
foram cultivados em meio de Stonebrink. As colônias resultantes foram submetidas à coloração de Ziehl-Neelsen e todos os isolados apresentaram características tintoriais de BAAR. Os 13 isolados de BAAR foram identificados por PCR multiplex (mPCR). 0 gene hsp65 foi alvo para identificação de Mycobacterium spp, a sequência de inserção IS6110 foi alvo para identificação de complexo Mycobacterium tuberculosis (CMT) e a região rvd1rv2031c foi explorada para detecção de $M$. bovis. Os isolados micobacterianos foram genotipados pela técnica de spoligotyping. Dos 13 bovinos, sete tinham pelo menos uma lesão sugestiva de tuberculose em linfonodos retrofaríngeos, parotídeos e pulmonares ou no pulmão, e em seis não foram encontradas lesões visíveis sugestivas da doença. Na mPCR, 11/13 $(84,6 \%)$ isolados foram positivos para Mycobacterium spp; $8 / 13(61,5 \%)$ positivos para CMT e $7 / 13$ (53,8\%) positivos para $M$. bovis. Com base no spoligotyping, oito isolados de BAAR foram agrupados dentro de três diferentes agrupamentos de genótipos e uma amostra remanescente apresentou perfil único, sendo quatro isolados com padrão de espoligotipo SB0121, dois SB1145, dois SB0881 e um SB0140. A técnica de spoligotyping demonstrou que há diversidade genética entre os espoligotipos presentes no estado de Mato Grosso do Sul, embora predomine o perfil SB0121.

TERMOS DE INDEXAÇÃO: Mycobacterium bovis, identificação molecular, epidemiologia molecular, spoligotyping, tuberculose bovina.

\section{INTRODUÇÃO}

A tuberculose bovina é uma doença infecto contagiosa, causada por Mycobacterium bovis, um membro do complexo Mycobacterium tuberculosis (CMT). 0 diagnóstico presuntivo é realizado por meio de testes intradérmicos e inspeção de abate (Acha \& Szyfres 2001, Brasil 2006, OIE 2009). A combinação do isolamento micobacteriano em meio de cultura, a partir de tecidos bovinos, com a identificação e genotipagem molecular tem contribuído para melhor compreensão da epidemiologia das infecções por $M$. bovis, o que proporciona aumento na eficiência dos programas de controle da doença. Para este propósito, é necessário ter uma correlação entre genotipagem e dados epidemiológicos (Haddad et al. 2004).

Os dados de genotipagem molecular permitem distinguir os genótipos de $M$. bovis que são predominantes em uma área específica e como os focos múltiplos ocorrem. A técnica de spoligotyping baseia-se na amplificação por PCR do DNA no lócus denominado de região de repetição direta (direct repeat - DR), exclusivo do genoma de micobactérias do CMT, para detectar a presença ou ausência de espaçadores nesse lócus. A detecção é feita pela hibridação dos espaçadores a uma membrana, usando um minibloter (Kamerbeek et al. 1997).

Em Mato Grosso do Sul, o inquérito epidemiológico para determinar a prevalência da tuberculose bovina está em andamento, mas sem resultados oficiais até o momento. Nesse estado, existem alguns estudos pontuais envolvendo o teste intradérmico, exame bacteriológico e molecular de lesões post mortem sugestivas de tuberculose que demons- tram a presença da doença (Jorge 2001, Araújo et al. 2005, Azambuja 2010).

Diante do impacto negativo da infecção por $M$. bovis à saúde animal e humana é importante a comprovação da infecção por meio do isolamento do agente e sua caracterização molecular. Este estudo propôs isolar, identificar e genotipar micobactérias a partir de tecidos provenientes de bovinos positivos no teste intradérmico para o diagnóstico da tuberculose no estado de Mato Grosso do Sul, Brasil.

\section{MATERIAL E MÉTODOS}

Obtenção do material biológico. Foram objetos deste estudo bovinos reagentes positivos ao teste cervical comparativo (TCC) durante inquérito epidemiológico parcial da tuberculose bovina, realizado nas regiões do Planalto Sul e Norte do estado de Mato Grosso do Sul. 0 abate dos animais seguiu as normas do Programa Nacional de Controle e Erradicação da Brucelose e Tuberculose (PNCEBT). Durante o abate sanitário ou necropsia foram coletadas amostras teciduais de pulmão e linfonodos, com ou sem lesões sugestivas de tuberculose, dos 13 bovinos adultos positivos no TCC.

Os bovinos pertenciam a 9 rebanhos de exploração leiteira e um rebanho de corte, todos sem histórico de tuberculose. Tratava-se de pequenas propriedades, a maioria assentamentos rurais, que trabalhavam em regime de agricultura familiar, localizadas nos munícipios de Anaurilândia, Bandeirantes, Iguatemi, Itaquiraí, Mundo Novo, Paranhos, Tacuru, Terenos e Ponta Porã.

Cultivo. Em no máximo dois dias após a coleta, as amostras teciduais foram homogeneizadas e descontaminadas pelo método de Petroff (Petroff 1915). A mistura do homogeneizado com o descontaminante $\mathrm{NaOH} 4 \%$ foi incubada e, em seguida, neutralizada. A suspensão foi centrifugada e o sedimento inoculado em meio de cultura de Stonebrink (Corner 1994). As culturas foram incubadas a $37^{\circ} \mathrm{C}$ e o crescimento bacteriano foi verificado semanalmente por um período de, pelo menos, 90 dias. As amostras bacterianas obtidas foram coradas em lâminas histológicas pela coloração de Ziehl-Neelsen para a pesquisa de bacilos álcool-ácido resistentes (BAAR).

Identificação molecular. A extração de DNA dos isolados de BAAR foi realizada por meio de termólise (Mazars et al. 2001). Os DNA obtidos foram submetidos a duas PCR multiplex (mPCR) de acordo com Figueiredo et al. (2009). Em ambas foram empregados os oligonucleotídeos JB21 (5' TCGTCCGCTGATGCAAGTGC 3') e JB22 (5' CGTCCGCTGACCTCAAGAAG 3'), que amplificam um produto de 500 pares de base (pb) da sequência alvo rvd1rv2031c, para identificação de $M$. bovis (Rodríguez et al. 1995). Na primeira m-PCR, foram incluídos os oligonucleotídeos TB11 (5'ACCAACGATGGTGTGTCCAT 3') e TB12 (5' CTTGTCGAACCGCATACCCT 3'), que amplificam um produto de $439 \mathrm{pb}$ de $h s p 65$, presente no gênero Mycobacterium spp. (Telenti et al. 1993). Na segunda mPCR, foram incluídos oligonucleotídeos INS-1 (5' CGTGAGGGCATCGAGGTGGC 3') e INS-2 (5' GCGTAGGCGTCGGTGACAAA 3'), que amplificam um fragmento de 245 pb da sequência de inserção IS6110, presente nas micobactérias do CMT (Hermans et al. 1990). A análise dos produtos foi realizada por eletroforese em gel de agarose $3 \%$ e solução tampão TBE 1x (89 mM tris-borato, 2 mM EDTA) a uma voltagem de 120 volts, 400 mÅ durante 180 minutos, em migração paralela ao padrão de 100 pb (PCR Low Ladder Marker Set - Sigma ${ }^{\circledR}$ ). O gel foi corado com Sybr Gold (Invitrogen ${ }^{\circledR}$ ) e fotodocumentado em sistema Gel Doc XR (Bio-Rad ${ }^{\circledR}$ ). Os produtos de amplificação foram visualizados por meio do Software Quantity One (Bio-Rad ${ }^{\circledR}$ ).

Genotipagem de micobactérias. As micobactérias foram genotipados por spoligotyping, independente do resultado da 
identificação por mPCR, no Instituto Nacional de Tecnología Agropecuaria (INTA), em Buenos Aires - Argentina, de acordo com o descrito por Kamerbeek et al. (1997). A amplificação da região DR foi realizada em volume final de $50 \mu \mathrm{L}$, com $0,2 \mathrm{mM}$ de cada dNTP (10 mM tris- $\mathrm{HCl}, \mathrm{pH} 8,0 ; 50 \mathrm{mM} \mathrm{KCl}$ ), 1,5mM de $\mathrm{MgCl}_{2}, 20 \mathrm{pmol}$ de cada oligonucleotídeo (DRa e DRb), 1 U de Taq DNA polimerase e 10 ng de DNA. A PCR consistiu de uma desnaturação inicial a $96^{\circ} \mathrm{C}$ por 3 minutos, 20 ciclos a $96^{\circ} \mathrm{C}$ por 1 minuto, $55^{\circ} \mathrm{C}$ por 1 minuto e $72^{\circ} \mathrm{C}$ por 30 segundos, seguido por extensão final a $72^{\circ} \mathrm{C}$ por 5 minutos.

DNA de Mycobacterium bovis BCG e de M. tuberculosis H37Rv foram usados como controles positivos do experimento e água ultrapura como controle negativo.

Os produtos da PCR foram transferidos para uma membrana de nylon (Ocimum Biosolutions, INDIA) contendo 43 oligonucleotídeos, correspondentes às sequências espaçadoras conhecidas na região DR, com os quais foram hibridados. Após a incubação com o conjugado estreptavidina-peroxidase, os espaçadores foram detectados por quimiluminescência. A identificação oficial dos padrões de spoligotyping encontrados foi obtida no website mbovis.org (Smith \& Uptom 2011).

\section{RESULTADOS}

Dos 13 bovinos positivos no TCC, sete $(53,8 \%)$ tinham pelo menos uma lesão sugestiva de tuberculose em linfonodos retrofaríngeos, parotídeos e pulmonares ou no pulmão, e em $6(46,2 \%)$ não foram encontradas lesões sugestivas da doença. Todas as amostras teciduais coletadas dos bovinos positivos no TCC foram cultivadas e foram positivas no isolamento bacteriano. Os isolados provenientes de tecidos com lesões sugestivas de tuberculose apresentaram colônias pequenas, arredondadas, de coloração amarelo-pálida, com borda irregular e superfície granular, típicas de micobactérias. Em relação aos isolados provenientes dos fragmentos de tecidos sem lesão, quatro apresentaram colônias atípicas, de coloração amarelo ouro e duas com crescimento escasso, mas morfologia típica de $\mathrm{Myco-}$ bacterium bovis. Submetidos à coloração de Ziehl-Neelsen, todos os isolados apresentaram características tintoriais de BAAR.

Na PCR com os oligonucleotídeos TB11/TB12, identificou-se o gênero Mycobacterium spp. em 11/13 isolados $(84,6 \%)$. Na PCR com os oligonucleotídeos INS1/INS2 e JB21/JB22, identificou-se CMT e espécie M. bovis em 8/13 $(61,5 \%)$ e $7 / 13(53,8 \%)$ isolados, respectivamente.

Quatro espoligotipos previamente identificados na base de dados foram observados em 9/13 (69,2\%) isolados de BAAR. Três deles formaram agrupamentos de genótipos e um apresentou perfil único. Quatro isolados de BAAR apresentaram perfil de espoligotipo SB0121, dois SB1145, dois SB0881 e o perfil único SB0140.

0 perfil de espoligotipo mais frequente (SB0121) foi também o que apresentou menor concordância com os demais resultados, ou seja, duas amostras bacterianas que apresentaram esse perfil eram formadas por colônias atípicas, foram identificados por PCR como gênero Mycobacterium spp., mas não como micobactérias do CMT e da espécie M. bovis. Outra amostra com esse perfil de espoligotipo apresentou colônias típicas de $M$. bovis e foi identificada por PCR como do gênero Mycobacterium spp., CMT, mas não foi amplificada pelos oligonucleotídeos JB21/JB22. Fi-
Quadro 1. Lesões, isolamento de BAAR, PCR para detecção do gênero Mycobacterium spp., complexo M. tuberculosis e espécie $M$. bovis e perfis de espoligotipos de isolados de BAAR obtidos de tecidos de bovinos positivos no teste cervical comparativo no estado de Mato Grosso do Sul

\begin{tabular}{cccccccc}
\hline Bovino & Procedência & $\begin{array}{c}\text { Lesão } \\
\text { Culturas } \\
\text { BAAR }\end{array}$ & $\begin{array}{c}\text { TB11 } \\
/ 12\end{array}$ & $\begin{array}{c}\text { INS } \\
\text { JB21 } \\
\text { /22 }\end{array}$ & $\begin{array}{c}\text { Perfil de } \\
\text { espoligotipo }\end{array}$ \\
\hline 1 & Mundo Novo & - & atípica & - & - & - & PNI \\
2 & Terenos & - & atípica & + & - & - & SB0121 \\
3 & Tacuru & - & atípica & + & - & - & SB0121 \\
4 & Anaurilandia & - & atípica & + & - & - & PNI \\
5 & Anaurilandia a & + & típica & + & + & + & SB1145 \\
6 & Anaurilandia b & + & típica & + & + & + & SB1145 \\
7 & Iguatemi a & + & típica & + & + & + & SB0140 \\
8 & Iguatemi b & + & típica & + & + & + & PNI \\
9 & Bandeirantes & + & típica & + & + & + & SB0121 \\
10 & Ponta Porã a & + & típica & + & + & + & SB0881 \\
11 & Itaquiraí & - & típica & + & + & - & SB0121 \\
12 & Paranhos & + & típica & - & - & - & PNI \\
13 & Ponta Porã b & - & típica & + & + & + & SB0881
\end{tabular}

- Negativo, + positivo, a/b = animais da mesma propriedade, $\mathrm{PNI}=$ perfil não identificado.

nalmente, uma amostra SB0121 apresentou positividade em todos os testes realizados.

Os demais perfis de espoligotipos identificados, SB1145, SB0881 e SB0140, concordaram completamente com os outros resultados: colônias típicas de M. bovis e identificação por PCR como do gênero Mycobacterium spp., CMT e espécie M. bovis. Em relação aos quatro perfis de espoligotipos não identificados (PNI), apenas um apresentou positividade em todos os demais testes de identificação molecular realizados.

Os resultados de lesões, isolamento de BAAR, mPCR e spoligotyping estão sumarizados no quadro 1 . Os perfis dos espoligotipos e o fenograma deduzido estão na Figura 1 e a geolocalização na Figura 2.

\section{DISCUSSÃO}

Dos 13 bovinos submetidos à necropsia ou abate sanitário, em apenas sete foi possível encontrar lesões visíveis sugestivas de tuberculose, embora se tratasse de animais positivos no TCC. As lesões foram visualizadas com maior frequência em linfonodos retrofaríngeos, parotídeos, pulmonares e no pulmão. No entanto, com a generalização da infecção em alguns animais, essas também foram encontradas em outros tecidos. Os bovinos cujos órgãos não apresentaram lesões macroscópicas detectáveis $(6 / 13)$ poderiam estar recentemente infectados (Brasil 2006), pois o quadro lesional da tuberculose é complexo e varia consoante com o tempo e o tipo de evolução da doença. 0 reconhecimento das lesões macroscópicas associadas a esta doença, principalmente durante a inspeção sanitária de rotina nos matadouros, é muito importante no diagnóstico da infecção, sendo responsável pela identificação de focos nos rebanhos. No entanto, o encontro de lesões é dificultado pelo fato da inspeção de rotina não ser tão pormenorizada como nos casos de abates sanitários de animais positivos aos testes intradérmicos (Shitaye et al. 2006, Wilsmore \& Taylor 2008).

Amostras teciduais dos 13 bovinos positivos no TCC, com ou sem lesão macroscópica sugestiva de tuberculose, 


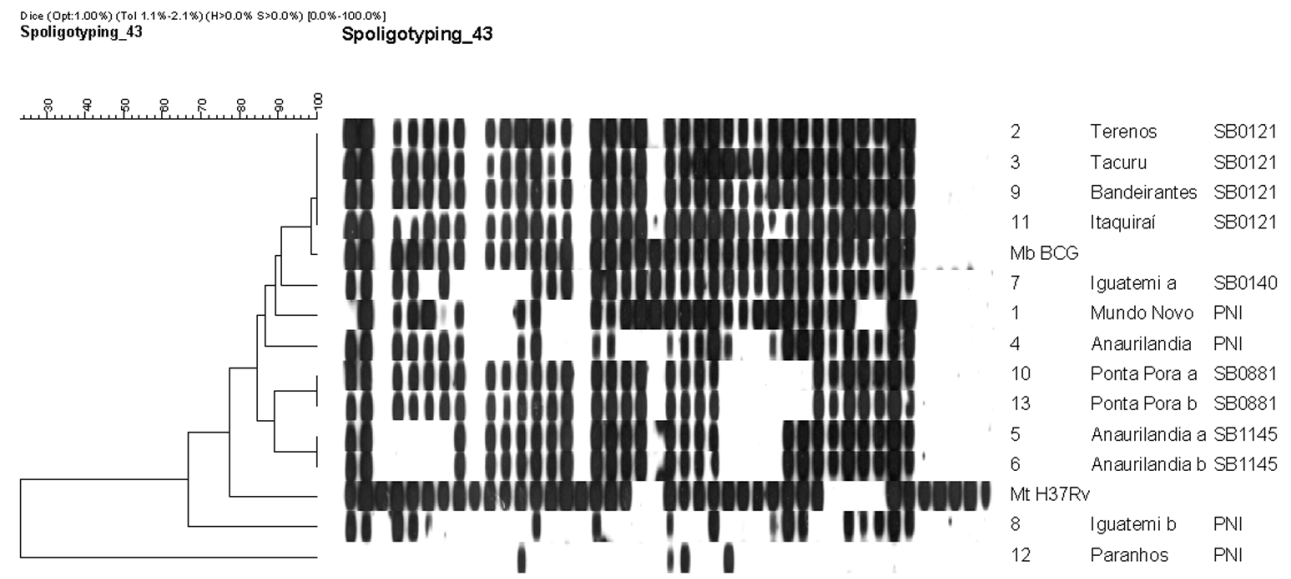

Fig.1. Perfis genotípicos dos espoligotipos obtidos de isolados de BAAR de tecido de bovinos positivos no teste intradérmico, procedentes do estado de Mato Grosso do Sul, Brasil, e das amostras padrão BCG de Mycobacterium bovis e H37Rv de M. tuberculosis, segundo anotação internacional (www.mbovis.org). 0 fenograma deduzido está ao lado esquerdo.

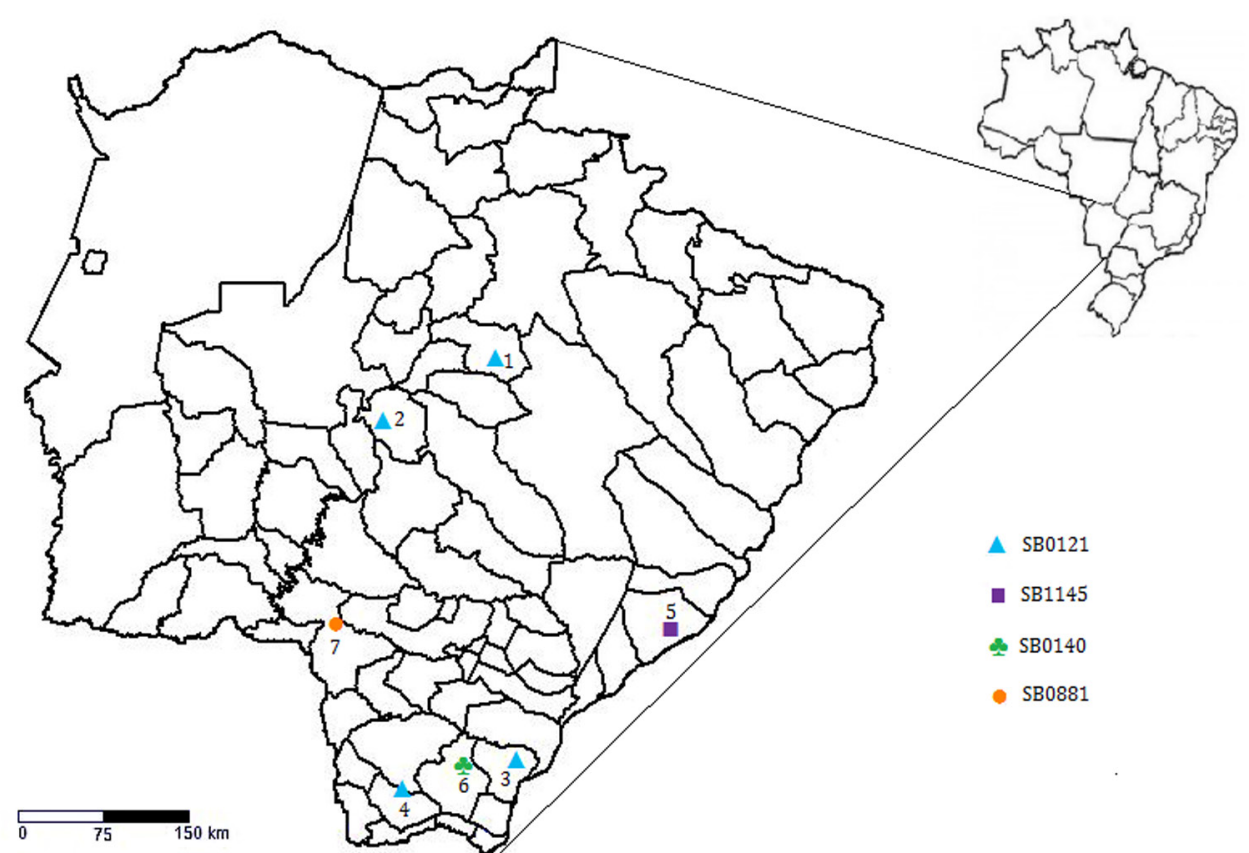

Fig.2. Localização geográfica dos isolados de BAAR genotipados por meio da técnica de spoligotyping encontrados no estado de Mato Grosso do Sul: Bandeirantes (1), Terenos (2), Itaquiraí (3), Tacuru (4), Anaurilândia (5), Iguatemi (6), Ponta Porã (7).

foram cultivadas e resultaram em isolamentos de BAAR. Possivelmente, o sucesso da recuperação de micobactérias em cultura deveu-se às condições favoráveis de coleta e de conservação das amostras, que devem ser feitas de maneira asséptica, dando preferência para tecidos intactos, acondicionadas em recipiente estéril e mantidas sob-refrigeração $\mathrm{de}+2^{\circ} \mathrm{C} \mathrm{a}+8^{\circ} \mathrm{C}$ para o transporte (CPZ 1988, OIE 2009). De acordo com Corner (2012), apesar da positividade no TCC, o diagnóstico da tuberculose bovina somente é confirmado após o isolamento e identificação de colônias de BAAR a partir dos tecidos.

As mPCR utilizadas nesse estudo identificaram 7/13 isolados de BAAR como gênero Mycobacterium spp., CMT e espécie $M$. bovis. Esses isolados eram colônias típicas de M. bovis. Nos demais isolados que também apresentaram colônias típicas, um foi identificado por mPCR como gênero Mycobacterium spp. e CMT (bovino 11), e em outro (bovino 12) não houve amplificação. Fatores como concentração de DNA na reação, variabilidade genética, além de possíveis inibidores da PCR presentes na reação poderiam justificar esses resultados (Michel et al. 2010). Além disso, em um estudo realizado por Sechi et al. (2000), concluiu-se que nem todas as cepas de $M$. bovis podem ser identificadas com oligonucleotídeos JB21/JB22 direcionados para o fragmento de $500 \mathrm{pb}$, uma vez que esse fragmento pode estar ausente, gerando resultados falso-negativos. Portanto, a adição de mais um par de oligonucleotídeos com alvo para uma sequência diferente, como em uma mPCR, diminui a ocorrência destes resultados (Figueiredo et al. 2010, Sales et al. 2014). 
Cabe destacar que os oligonucleotídeos JB21/JB22 foram inicialmente propostos como específicos para M. bovis (Rodríguez et al. 1995). No entanto, em estudo posterior, Rodríguez et al. (1999) verificaram que algumas cepas de M. tuberculosis também podiam ser amplificadas por eles. Há relatos de M. tuberculosis infectando bovinos (Ameni et al. 2011, Mbugi et al. 2012, Romero et al. 2011, Thakur et al. 2012). Entretanto, no Brasil, mais de 2000 culturas de lesões presuntivas de tuberculose bovina foram testadas para M. tuberculosis em laboratório de referência do Ministério da Agricultura, Pecuária e Abastecimento (MAPA) e não houve resultados positivos para esta espécie (Araújo et al. 2014). De qualquer modo, os benefícios da PCR baseada nessa sequência de 500 pb não podem ser menosprezados, uma vez que a amplificação é indicativa da presença do agente infeccioso causador da tuberculose bovina (Rodríguez et al. 1999).

Entre os quatro isolados de BAAR que apresentaram colônias atípicas, três (75\%) foram identificados apenas como gênero Mycobacterium spp. (Quadro 1). Essa identificação pode referir-se a contaminação por micobactérias atípicas, de crescimento rápido, que muitas vezes inibem o crescimento do patógeno presente na forma paucibacilar da tuberculose bovina (OIE 2009), característica que dificulta o diagnóstico. Essa situação foi verificada por meio da técnica PRA-hsp65 que resultou em padrão compatível com M. avium subsp. avium tipo 5 ou M. colombiense tipo 1 (dados não mostrados).

A pesquisa dos espoligotipos foi uma importante ferramenta para discriminar os genótipos de $M$. bovis presentes nos rebanhos bovinos de Mato Grosso do Sul. No presente estudo, foram identificados quatro espoligotipos - SB0121, SB1145, SB0140 e SB0881- com deleções nos espaçadores de 3, 9, 16 e 39-43, o que é característico de cepas de M. bovis (Kamerbeek et al. 1997, Haddad et al. 2004).

Em nove isolados de BAAR, foram encontrados espoligotipos da espécie $M$. bovis mesmo que desses, dois eram provenientes de animais sem lesões visíveis ao abate, mas com colônias típicas (bovinos 11 e 13). A PCR identificou o DNA isolado do bovino 11 como Mycobacterium spp. e CMT; do bovino 13 como Mycobacterium spp., CMT e da espécie M. bovis. Nesse caso, a técnica de spoligotyping foi importante também para identificar a espécie M. bovis. Outros dois isolados de BAAR (bovinos 2 e 3) eram colônias atípicas identificadas por PCR apenas como Mycobacterium spp. $\mathrm{O}$ isolamento concomitante de micobactérias atipícas, cujo crescimento costuma ser rápido e abundante, pode ter inibido o crescimento de colônias de $M$. bovis, que é lento e escasso (Corner 1994). Ainda assim, por se tratar de uma técnica que requer menor concentração de DNA o spoligotyping foi capaz de indentificar M. bovis e discriminar o perfil de espoligotipo (Kamerbeek et al. 1997, Sola et al. 1999).

A técnica de spoligotyping não identificou perfís de espoligotipos em 4/13 isolados de BAAR. Dois isolados (bovino 1 e 4) eram colônias atípicas provenientes de bovinos sem lesões visíveis ao abate e a PCR identificou como Mycobacterium spp. apenas o DNA do isolado do bovino 4.
Por outro lado, em um isolado (bovino 12) proveniente de bovino com lesão tecidual não houve amplificação de DNA com os oligonucleotídeos TB11/12, INS1/2 e JB21/22. Já no spoligotyping, o padrão de espoligotipo encontrado foi incompleto (Fig.1), possivelmente por não haver DNA suficiente para amplificação da região alvo.

No isolado proveniente do bovino 8, seu perfil de espoligotipo não foi identificado, mesmo com a presença de lesão tecidual e a amplificação do DNA com os três pares de oligonucleotídeos utilizados. Esse resultado pode significar a descoberta de um novo perfil de espoligotipo ainda não anotado no banco de dados (www.mbovis.org), possivelmente porque essa cepa se encontra em baixa proporção na população de $M$. bovis da regiao estudada.

Haddad et al. (2004) sugeriram a existência de dois grupos de espoligotipos dominantes, o primeiro com SB0120 (estirpe BCG ancestral) e SB0121, este último diferindo da estirpe original apenas pela perda do espaçador 21. Este grupo é frequente em países como Itália, França, Bélgica, Espanha e Portugal. O segundo grupo, representado por SB0140, presente na Inglaterra. De acordo com essa teoria, os tipos de ancestrais tornaram-se o padrão dominante nos países onde foram introduzidos ou evoluíram para espoligotipos semelhantes. 0 resultado deste trabalho mostrou que o perfil de espoligotipo predominante em Mato Grosso do Sul foi o SB0121, também identificado no estado de São Paulo (Rodriguez et al. 2004, Rocha et al. 2013). Nos estados de Minas Gerais, Mato Grosso do Sul e Paraíba sua presença também já foi relatada (Parreiras et al. 2012). Segundo Zumárraga et al. (2013), esse espoligotipo é o mais prevalente no Brasil, presente também no México e na Venezuela, mas não detectado na Argentina. Na Europa, esse espoligotipo é frequentemente relatado na França (Haddad et al. 2001), Espanha (Rodríguez et al. 2010) e Portugal (Duarte et al. 2008). Curiosamente, nesse estudo, observou-se que a maior parte dos isolados com esse espoligotipo (3/4) era proveniente de bovinos sem lesoes visíveis, o que pode sugerir baixa virulência (Garbaccio et al. 2014), embora não se conhecesse o estágio de evolução da doença.

0 espoligotipo SB0140 também já foi detectado no estado de São Paulo (Rocha et al. 2013), porém Zumárraga et al. (2013) consideram sua frequência baixa no Brasil. É predominante nos países vizinhos, Argentina e Chile e já foi relatado no Reino Unido, Nova Zelândia, Austrália e Irlanda (Cousins et al. 1998, Costello et al. 1999, Zumárraga et al. 1999, Haddad et al. 2001, Smith et al. 2011).

O espoligotipo SB0881, caracterizado pela ausência dos espaçadores 21 e 26-30 (Zumárraga et al. 2013), foi relatado anteriormente em São Paulo (Rocha et al. 2013) e é o terceiro mais encontrado no Brasil (Zumárraga et al. 2013). Também já foi relatado na França e na Espanha (Haddad et al. 2001, Rodríguez et al. 2010).

O espoligotipo SB1145 foi previamente referido apenas no Brasil (www.mbovis.org) em isolados de Minas Gerais (Parreiras et al. 2012).

Os quatro espoligotipos identificados nesse estudo, os predominantes na América Latina e aqueles presentes em países europeus, possuem similaridade, possivelmente por consequência das relações econômicas entre esses países 
ocorridas a partir da metade do século XIX, quando a importação de bovinos era principalmente de origem europeia (Zumárraga et al. 2013).

Cepas presentes em diferentes estados com o mesmo padrão de espoligotipo podem ser resultantes da movimentação de animais contaminados entre diferentes regiões (Zumárraga et al. 2013) ou de homoplasia (Comas \& Gagneux 2009). A movimentação de animais doentes acontece pela dificuldade em distinguir animais anérgicos no teste de intradermorreação com PPD e por falhas de saneamento dos focos ou no controle de trânsito animal (Lepper et al. 1977). 0 perfil SB0121 foi encontrado em diferentes municípios de Mato Grosso do Sul, o que também pode ser justificado pela movimentação de animais. Não foi identificada a presença de diferentes perfis genotípicos de M. bovis em propriedades que apresentaram dois animais positivos.

A aplicação da técnica de spoligotyping, em isolados de BAAR obtidos a partir de amostras teciduais de bovinos positivos no TCC em diferentes municípios de Mato Grosso do Sul, demonstra que há diversidade genética entre os espoligotipos presentes no estado, embora predomine o perfil SB0121.

A associação das técnicas de diagnóstico ante-mortem da tuberculose, preconizadas pelo PNCEBT, com técnicas de identificação e genotipagem molecular, facilitam as atividades de saneamento, incluindo a vigilância de doenças e a investigação de surtos, identificando padrões de transmissão e fatores de risco. Além disso, em combinação com dados espaciais, destaca a distribuição geográfica de cepas de $M$. bovis. Dessa forma, contribui para eficiência dos programas de controle e erradicação da tuberculose.

Agradecimentos.- À equipe do Ministério da Agricultura Pecuária e Abastecimento (MAPA), da Universidade de São Paulo (USP) e da Agência Estadual de Defesa Sanitária Animal e Vegetal de Mato Grosso do Sul (IAGRO), responsável pelo planejamento do inquérito epidemiológico da tuberculose bovina.

\section{REFERÊNCIAS}

Acha P.N. \& Szyfres B. 2001. Zoonosis y Enfermedades Transmisibles Comunes al Hombre y a los Animales. Organización Panamericana de la Salud. Vol.3. 3르 ed. Organización Panamericana de la Salud, Washington, DC. 271p.

Ameni G., Vordermeier M., Firdessa R., Aseffa A., Hewinson G., Gordon S.V. \& Berg S. 2011. Mycobacterium tuberculosis infection in grazing cattle in central Ethiopia. Vet. J. 188(3):359-361.

Araújo C.P., Leite C.Q.F., Prince K.A., Jorge K.S.G. \& Osório A.L.A.R. 2005. Mycobacterium bovis identification by a molecular method from post-mortem inspected cattle obtained in abattoirs of Mato Grosso do Sul, Brazil. Mem. Inst. Oswaldo Cruz 100(7):749-752.

Araújo C.P., Osório A.L.A.R., Jorge K.S.G., Ramos C.A.N., Filho A.F.S., Vidal C.E.S., Roxo E., Nishibe C., Almeida N.F., Júnior A.A.F., Silva M.R., Neto J.D.B., Cerqueira V.D., Zumárraga M.J. \& Araújo F.R. 2014. Detection of Mycobacterium bovis in Bovine and Bubaline Tissues Using Nested-PCR for TbD1. Plos One 9(3):e91023.

Azambuja A.D. 2010. Estratégias de diagnóstico da tuberculose bovina. Dissertação de Mestrado em Ciência Animal, Universidade Federal de Mato Grosso do Sul, Campo Grande, MS.

Brasil 2006. Programa Nacional de Controle e Erradicação da Brucelose e da Tuberculose Animal (PNCEBT). Ministério da Agricultura, Pecuária e Abastecimento, Brasília, DF.

CPZ 1988. Bacteriologia de la Tuberculosis. Centro Panamericano de Zo- onosis, Buenos Aires.

Comas I. \& Gagneux S. 2009. The Past and Future of Tuberculosis Research. Plos Pathog. 5(10):e1000600.

Corner L.A. 1994. Postmortem diagnosis of Mycobacterium bovis infection in cattle. Vet. Microbiol. 40(1/2):53-63.

Costello E., O'Grady D., Flynn O., O’Brien R., Rogers M., Quigley F., Egan J. \& Griffin J. 1999. Study of restriction fragment length polymorphism analysis and spoligotyping for epidemiological investigation of Mycobacterium bovis infection. J. Clin. Microbiol. 37(10):3217-3222.

Corner L.A.L., Gormley E. \& Pfeiffer D.U. 2012. Primary isolation of $M y$ cobacterium bovis from bovine tissues: Conditions for maximizing the number of positive cultures. Vet. Microbiol. 156(1-2):162-171.

Cousins D., Williams S., Liébana E., Aranaz A., Bunschoten A., Van Embden J.D.A. \& Ellis T. 1998. Evaluation of four DNA typing techniques in epidemiological investigations of bovine tuberculosis. J. Clin. Microbiol. 36(1):168-178.

Duarte E.L., Domingos M., Amado A. \& Botelho A. 2008. Spoligotype diversity of Mycobacterium bovis and Mycobacterium caprae animal isolates. Vet. Microbiol. 130(3-4):415-421.

Figueiredo E.E.S., Silvestre F.G., Campos W.N., Furlanetto L., Medeiros L., Lilenbaum W., Fonseca L.S., Silva J.T. \& Paschoalin V. 2009. Identification of Mycobacterium bovis isolates by a multiplex PCR. Braz. J. Microbiol. 40:231-233.

Figueiredo S.M., Rocha V.C.M. Higino S.S.S., Batista C.S.A., Alves C.J., Clementino I.J. \& Azevedo S.S. 2010. Tuberculose bovina no Estado da Paraíba: estudo retrospectivo. Pesq. Vet. Bras. 30(9):712-716.

Garbaccio S., Macias A., Shimizu E., Paolicchi F., Pezzone N., Magnano G., Zapata L., Abdala A., Tarabla H., Peyru M., Caimi K., Zumárraga M., Canal A. \& Cataldi A. 2014. Association between spoligotype-VNTR types and virulence of Mycobacterium bovis in cattle. Virulence 5(2):297-302.

Haddad N., Ostyn A., Karoui C., Masselot M., Thorel M.F., Hughes S.L., Inwald J., Hewinson R.G. \& Durand B. 2001. Spoligotype diversity of $M y$ cobacterium bovis strains isolated in France from 1979 to 2000. J. Clin. Microbiol. 39(10):3623-3632.

Haddad N., Masselot M. \& Durand B. 2004. Molecular differention of Mycobacterium bovis isolates: review of main techniques and applications. Res. Vet. Sci. 76(1):1-18.

Hermans P.W., Van Soolingen D., Dale J.W., Schuitema A.R., McAdam R.A., Catty D. \& Van Embden J.D. 1990. Insertion element IS986 from Mycobacterium tuberculosis: a useful tool for diagnosis and epidemiology of tuberculosis. J. Clin. Microbiol. 28(9):2051-2058.

Jorge K.S.G. 2001. Aplicação de testes específicos e presuntivos para o diagnóstico da tuberculose bovina no estado de Mato Grosso do Sul, Brasil. Dissertação de Mestrado em Biologia, Universidade Federal de Mato Grosso do Sul, Campo Grande, MS.

Kamerbeek J., Schouls L., Kolk A., Van Agterveld M., Van Soolingen D., Kuijper S., Bunschoten A., Molhuizen H., Shaw R., Goyal M. \& Van Embden J. 1997. Simultaneous detection and strain differentiation of Mycobacterium tuberculosis for diagnosis and epidemiology. J. Clin. Microbiol. 35(4):907-914.

Lepper A.W.D., Pearson C.W. \& Corner L.A. 1977. Anergy to tuberculin in beef-cattle. Aust. Vet. J. 53(5):214-216.

Mazars E., Lesjean S., Banuls A., Gilbert M., Vicent V., Gicquel B., Tibayrebnc M., Locht C. \& Supply P. 2001. High-resolution minisatellite-based typing as a portable approach to global analysis of Mycobacterium tuberculosis molecular epidemiology. Proc. Natl Acad. Sci. USA. 98(4):1901-1906.

Mbugi E.V., Katale B.Z., Kendall S., Good L., Kibiki G.S., Keyyu J.D., GodfreyFaussett P., Van Helden P. \& Matee M.I. 2012. Tuberculosis cross-species transmission in Tanzania: Towards a One-Health concept. Onderstepoort. J. Vet. Res. 79(2):501.

Michel A.L., Muller B. \& Van Helden P.D. 2010. Mycobacterium bovis at the animal-human interface: a problem, or not? Vet. Microbiol. 140(3/4): 371-378.

OIE 2009. Manual of Diagnostic Tests and Vaccines for Terrestrial Animals. 5th ed. World Organization for Animal Health, Paris. 
Petroff S.A. 1915. A new and rapid method for the isolation and cultivation of tubercle bacilli directly from the sputum and feces. J. Exp. Med. 21(1):38-42.

Parreiras P. M., Andrade G. I., Nascimento T.F., Oelemann M.C., Gomes H.M., Alencar A.P., Assis R.A., Mota P.M.P.C., Pereira M.A.S., Lobato F.C.F., Lage A.P. \& Suffys P.N. 2012. Spoligotyping and variable number tandem repeat analysis of Mycobacterium bovis isolates from cattle in Brazil. Mem. Inst. Oswaldo Cruz 107(1):64-73.

Rocha V.C.F., Figueiredo S.C., Rosales C.A.R., Hildebrand J.H.F.G., Keid L.B., Soares R.M. \& Ferreira Neto J.S. 2013. Molecular discrimination of Mycobacterium bovis in São Paulo, Brazil. Vector Borne Zoonotic Diseases 13(1):17-21.

Rodríguez J.G., Mejia G.A., Del Protillo P., Patarroyo M.E. \& Murilo L.A. 1995. Species-specific identification of Mycobacterium bovis by PCR. Microbiol. 141:2131-2138.

Rodríguez J.G., Fissanoti J.C., Del Portillo P., Patarroyo M.E., Romano M.I. \& Cataldi A. 1999. Amplification of 500-base-pair fragment from isolates of Mycobacterium bovis. J. Clin. Microbiol. 37(7):2330-2332.

Rodriguez C.A.R., Zumárraga M.J., Oliveira E.M., CataldI A.A., Romano M.I., Otto H.H., Bonafé V.L. \& Ferreira Neto J.S. 2004. Caracterização molecular de isolados de Mycobacterium bovis do Estado de São Paulo Brasil, utilizando a técnica de spoligotyping. Arqs Inst. Biológico, São Paulo, 71(1):277-282.

Rodríguez S., Romero B., Bezos J., De Juan L., Alvarez J., Castellanos E., Moya N., Lozano F., González S., Sáez-Llorente J.L., Mateos A., Domínguez L. \& Aranaz A. 2010. High spoligotype diversity within a Mycobacterium bovis population: clues to understanding the demography of the pathogen in Europe. Vet. Microbiol. 141(1/2):89-95.

Romero B., Rodríguez S., Bezos J., Díaz R., Copano M.F., Merediz I., Mínguez O., Marqués S., Palacios J.J., Viedma D.G., Sáez J.L., Mateos A., Aranaz A., Domínguez L. \& Juan L. 2011. Humans as source of Mycobacterium tuberculosis infection in cattle, Spain. Emerg. Infect. Dis. 17(12):23932395.

Sechi L.A., Duprè I., Leori G., Fadda G. \& Zanetti S. 2000. Distribution of a Specific 500-Base-Pair Fragment of Mycobacterium bovis Isolates from Sardinian Cattle. J. Clin. Microbiol. 38(10):3837-3839.
Sales M.L., Fonseca Jr A.A., Sales E.B., Cottorello A.C., Issa M.A., Hodon M.A., Soares-Filho P.M., Ramalho A.K., Silva M.R., Lage A.P. \& Heinemann M.B. 2014. Evaluation of molecular markers for the diagnosis of Mycobacterium bovis. Folia Microbiol. 59(5):433-438.

Shitaye J.E., Getahun B., Alemayehu T., Skoric M., Treml F., Fictum P., Vrbas V. \& Pavlik I. 2006. A prevalence study of bovine tuberculosis by using abattoir meat inspection and tuberculin skin testing data, histopathological and IS6110 PCR examination of tissues with tuberculous lesions in cattle in Ethiopia. Vet. Med. Czech. 51(11):512-522.

Smith N.H. \& Upton P. 2011. Naming spoligotype patterns for the RD9-deleted lineage of the Mycobacterium tuberculosis complex: www.Mbovis. org. Infect. Genet. Evol. 12(4):873-876.

Sola C., Devallois A., Horgen L., Maisetti J., Filliol I., Legrand E. \& Rastogi N. 1999. Tuberculosis in Caribbean: using spacer oligonucleotide typing to understand strain origin and transmission. Emerg. Infect. Dis. 5(3):404414.

Telenti A., Marchesi F., Balz M., Bally F., Bottger E.C. \& Bodmer T. 1993. Rapid identification of mycobacteria to the species level by polymerase chain reaction and restriction enzyme analysis. J. Clin. Microbiol. 31(2):175-178.

Thakur A., Sharma M., Katoch V.C., Dhar P. \& Katoch R.C. 2012. Detection of Mycobacterium bovis and Mycobacterium tuberculosis from Cattle: Possible Public Health Relevance. Indian J. Microbiol. 52(2):289-291.

Wilsmore T. \& Taylor N. 2008. Bovine Tuberculosis: an update. Veterinary Epidemiology and Economics Research Unit, University of Reading, UK. $132 p$.

Zumárraga M.J., Martin C., Samper S., Alito A., Latini O., Bigi F., Roxo E., Cicuta M.E., Errico F., Ramos M.C., Cataldi A., Van Soolingen D. \& Romano M.I .1999. Usefulness of spoligotyping in molecular epidemiology of $M y$ cobacterium bovis-related infections in South America. J. Clin. Microbiol. 37(2):296-303.

Zumárraga M.J., Arriaga C., Barandiaran S., Cobos-Marín L., De Waard J., Estrada-Garcia I., Figueiredo T., Figueroa A., Giménez F., Gomes H.M., Gonzalez-y-Merchand J.A., Macías A., Milián-Suazo F., Rodríguez C.A.R., Santillán M.A., Suffys P.N., Trangoni M.D., Zárraga A.M. \& Cataldi A. 2013. Understanding the relationship between Mycobacterium bovis spoligotypes from cattle in Latin American Countries. Res. Vet. Sci. 94(1):9-21. 